\title{
Multimodal imaging of retinal pigment epithelial detachments in patients with C3 glomerulopathy: case report and review of the literature
}

\author{
Valeria Kheir ${ }^{1 \dagger}$, Ali Dirani ${ }^{1 \dagger}$, Matthieu Halfon ${ }^{2}$, Jean-Pierre Venetz ${ }^{3}$, Georges Halabi ${ }^{2}$ and Yan Guex-Crosier ${ }^{1 *}$
}

\begin{abstract}
Background: To describe the optical coherence tomography angiograhy (OCTA) of drusenoid pigment epithelial detachments (PEDs) in a woman affected by Complement 3 (C3) glomerulopathy, which represents a spectrum of glomerular diseases characterized on fluorescent microscopy by C3 accumulation with absent, or scanty, immunoglobulin deposits. It is due to acquired or genetically defective alternative pathway control and is generally associated with drusen-like deposits in Bruch's membrane, as well as choriocapillaris. These retinal lesions can be associated with choroidal neovascularization and central serous chorioretinopathy (CSCR). OCTA is useful to detect neovascularization without injecting a contrast product, particularly in these patients who may have renal insufficiency.
\end{abstract}

Case presentation: A 28-year-old woman affected by C3 glomerulpathy was diagnosed with asymptomatic multiple bilateral PEDs during a routine ophthalmologic consultation. To better characterize the lesions, multimodal imaging was performed and included: optic coherence tomography (OCT), en-face OCT, OCTA, fluorescence and indocyanine angiography. The OCTA clearly identified vascular network rarefaction with decreased choriocapillary vascularization. It confirmed that PEDs associated with C3 glomerulonephritis are not vascularized, but rather of serous type.

Conclusions: Patients affected by C3 glomerulopathy can develop neovascular membranes as retinal complications of pigment epithelial detachments. Optical coherence angiography may be indicated to identify this complication, without injecting any contrast product that could produce further kidney damage.

Keywords: Complement 3 glomerulopathy, Drusenoid pigment epithelial detachments, Alternative pathway, Multimodal imaging, Optic coherence tomography angiography, Choroidal neovascularization

\section{Background}

Complement 3 (C3) glomerulopathy is a rare group of glomerular diseases. Presenting features include proteinuria, sometimes with nephrotic syndrome, hematuria, hypertension and renal failure. It mostly affects older children, adolescents and young adults. It is characterized by $\mathrm{C} 3$ deposits in the mesangium and along the glomerular basement membrane (GBM). In some patients, C3 glomerulopathy can be associated with retinal

\footnotetext{
* Correspondence: yan.guex@fa2.ch

${ }^{\dagger}$ Equal contributors

'Jules Gonin Eye Hospital, Department of Ophthalmology, University of

Lausanne, Ave de France 15, 1000 Lausanne 2, Switzerland

Full list of author information is available at the end of the article
}

lesions described as drusen-like deposits in Bruch's membrane and choriocapillaris. Thickening of GBM along with glomerular proliferative lesions induce impairment of glomerular filtration, hematuria, proteinuria and at end stage a loss of renal function. In the eye, thickening of Bruch's membrane and subendothelial/ subepithelial deposits induce the formation of drusen, predisposing to a risk of decreased vision $[1,2]$.

We present a patient with C3 glomerulopathy associated with retinal lesions, and report multimodal imaging findings. We also report a review of the literature of published cases of patients with C3 glomerulopathy 
associated with retinal findings, with a special focus on imaging studies.

\section{Case presentation}

A 28-year-old female, known to have C3 glomerulopathy, presented to our clinic for a routine check-up and was found to have asymptomatic multiple bilateral retinal pigment epithelium detachments (PEDs). At twelve years of age, the patient suffered a nephrotic syndrome, and a first renal biopsy revealed diffuse membranoproliferative glomerulonephritis (MPGN). This was treated with oral corticosteroids and cyclophosphamide and was maintained on azathioprine. Relapse occurred after a five-year period of remission, and a new renal biopsy showed a membranoproliferative glomerulonephritis of type I (MPGNI). Immunofluorescence assay was positive for deposits of $\mathrm{C} 3$ complement, and the diagnosis of $\mathrm{C} 3$ glomerulonephritis (C3GN) was confirmed. The electronic microscopy of a glomerulus showed that the deposits were localized in a subendothelial manner, as typically seen in C3 Glomerulonephritis C3GN (former MPGN type 1). (Figure 1). Secondary causes of C3GN were excluded by a complete workup: hepatitis B and $\mathrm{C}$ serology, cryoglobulinemia, absence of monoclonal gammapathy on serum electrophoresis. Complementary exploration in the serum confirmed an activation of the alternative pathway: C3 low at $0.23 \mathrm{~g} / \mathrm{l}$ ( $\mathrm{n}: 0.75-1.4$ ), C4 normal at $0.26 \mathrm{~g} / \mathrm{l}$ (n: 0.10-0.34), C5B9 elevated at $551.4 \mathrm{ng} / \mathrm{ml}$ (n: $127-303$ ) and $\mathrm{CH} 50$ at 23\% (n: 70140\%). Genetic and acquired autoantibodies (C3 nephritic factor, anti-factor $\mathrm{H}$ antibodies) investigations were negative. Treatment with low-dose cyclosporine resulted in stabilization of the disease for a further 5 years. At

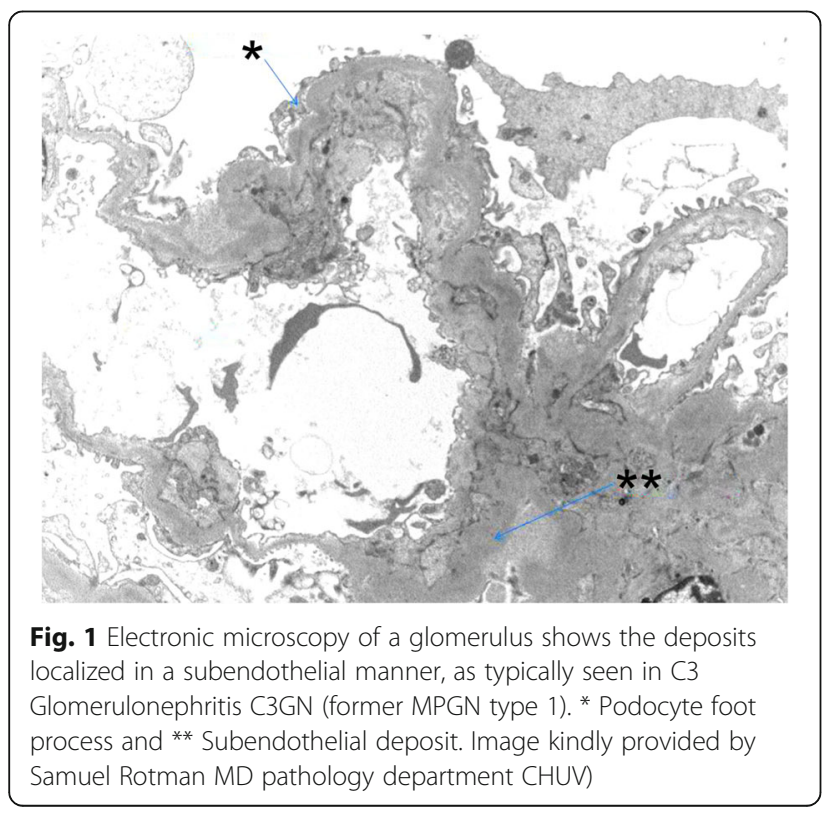

this point multiple relapses occurred with recurrence of proteinuria and decrease in renal function, treated with cyclosporine, followed by intravenous IV Rituximab. Despite the use of immunosuppressant drugs, proteinuria progressively worsened and renal function deteriorated. Peritoneal dialysis was started 1 year ago and the patient is currently evaluated for a renal graft. She is also on acenocoumarol for a factor $\mathrm{V}$ Leiden.

At presentation, the patient had a routine ophthalmologic examination: best corrected visual acuity was $12 / 10$ in both eyes, bilateral anterior segment examination was unremarkable, eye pressure was normal in both eyes. Fundus examination revealed more than 50 yellowish subepithelial drusen-like elevations in macula, midperiphery and periphery of both eyes. Spectral domain optical coherence tomography (SD OCT) showed that these lesions were PEDs with serous content (Fig. 2). Choroidal thickness evaluated by enhanced depth OCT was $328 \mu \mathrm{m}$ in the right eye and $271 \mu \mathrm{m}$ in the left eye. En-face OCT showed PED at different regions of the retina and clearly localized the deposits between the subepithelial space and the external limiting membrane (Fig. 3). Fluorescence angiography (FA) revealed hyperfluorescent well circumscribed lesions in a greater number than those observed in the fundus on early and late time frames, with no evidence of leakage. Indocyanine angiography showed late hypercyanescence of the retinal lesions in both eyes (Fig. 4). Optical coherence angiography (OCTA) of the superficial and deep capillary plexuses revealed no abnormalities. OCTA of the outer retina and choriocapillaris layers did not show any abnormal vascular membranes associated with PEDs, but vascular network rarefaction was clearly identified with fewer blood vessels in the choriocapillaris layer (Fig. 5). OCT angiography (OCTA) confirmed that PEDs associated with C3 glomerulonephritis were not vascularized but rather of serous type. Vascular abnormalities seen in the choriocapillaris layer may play a role in the pathogenesis, or simply represent a consequence of material accumulation in PED associated with C3 glomerulonephritis.

The patient was followed regularly in our department. At her last follow up visit (2 years after presentation), she presented asymptomatic bilateral papillary edema (Fig. 6). Visual acuity was still 12/10 in both eyes, color vision (Ishihara pseudoisochromatic chart) was normal in both eyes, visual field was normal in right eye but showed small superior defects in the left eye. Anterior biomicroscopy was normal and bilateral PEDs remained present. Retinal nerve fiber layer thickness in the peripapillary area was increased: $248 \mu \mathrm{m}$ in the right eye, and $264 \mu \mathrm{m}$ in the left eye. Cerebral magnetic resonance imaging (MRI) was performed and revealed primary intracranial hypertension, for which she was referred to the neurosurgeons. 

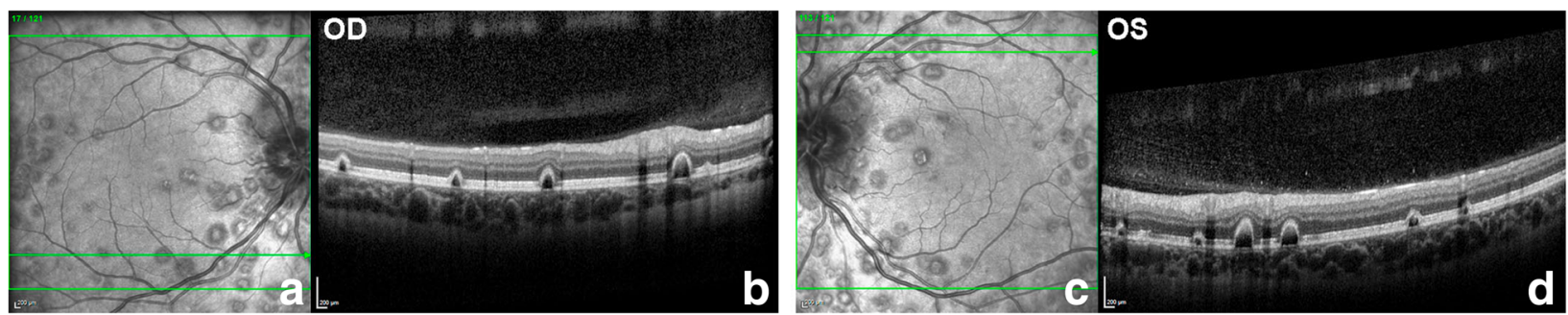

Fig. 2 a. RE IR photography. b. RE OCT section performed through drusen. c. LE IR photography. d. LE OCT section performed through drusen. Multiple PEDs with serous content are visible on OCT

\section{Discussion and conclusions}

In the past, classification of membranoproliferative glomerulopathy (MPGN) was based on pathological findings of electron microscopy, and 3 types of MPGN were described: type I is characterized by subendothelial deposits, type II or dense deposit disease (DDD) by glomerular basement membrane dense deposits, and type III by both subepithelial and subendothelial deposits [3]. Recently, a new classification has been proposed based on immunofluorescence microscopy: immune complex-mediated glomerulonephritis and complement-mediated glomerulonephritis $[1,4]$. The new classification is more appropriate as it better reflects the underlying pathophysiology of the disease.

MPGN types I and III have been reclassified in complement 3 glomerulonephritis $(\mathrm{C} 3 \mathrm{GN})$, characterized by discrete deposits in the mesangium, and subendothelial and subepithelial capillary walls. MPGN II and C3GN are complement-mediated glomerular disease and are part of C3 glomerulopathies, these characterized by complement 3 deposits with absent or scant immunoglobulin deposits on fluorescent microscopy. C3 glomerulopathies represent a spectrum of glomerular diseases due to defective alternative pathway control $[1,2]$. The alternative pathway

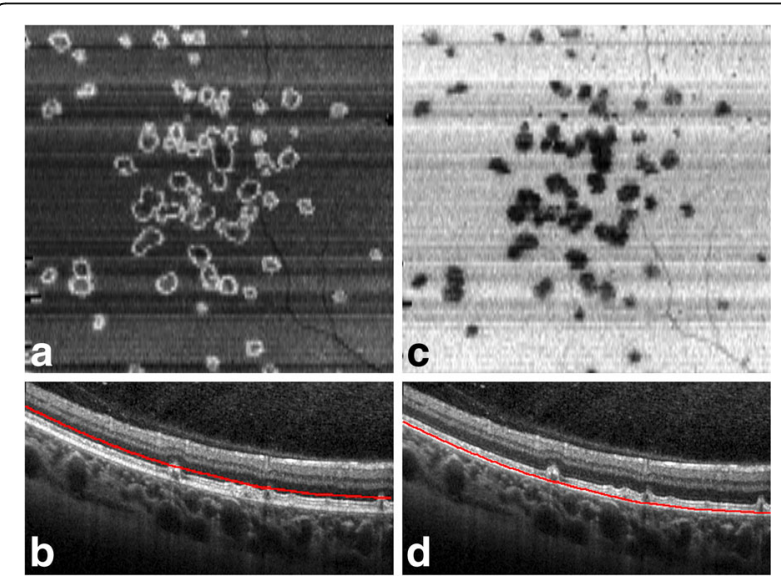

Fig. $3 \mathbf{a}$ and (b): RE Enface OCT at the external limiting membrane level. $\mathbf{c}$ and (d): RE Enface OCT at the RPE level. The deposits extend between the subepithelial space and external limiting membrane recognizes and eliminates microbes or modified cells. It is now recognized that not only MPGN II, but also C3GN, can be accompanied by retinal drusen.

The choriocapillaris-Bruch membrane-retinal pigment epithelium (RPE) interface is anatomically similar to the capillary tuft-GBM-glomerular epithelial interface [5]. These organs lack local membrane-bound complement regulators, thus they are vulnerable to injury caused by products of uncontrolled alternative pathway. Deposits in retina and kidney have the same structure and composition [6].

Drusen are defined as deposits within Bruch's membrane and are a hallmark feature of age-related macular degeneration (AMD). These lesions have been largely described in MPGN type II since 1989 [5-20], but the first description of drusen in MPGN type I was given in 2009 [21]. In a case report, Han et al. reported the presence of multiple "drusens" and "PEDs". In 2001, Mullins et al. analyzed the structure and composition of drusen in MPGN and in poststreptococcal GN, and compared them with drusen in AMD. They found that the drusen have a similar composition in both types of membranous GN and in AMD: vitronectin (inhibitor of complement), complement C5, complement C5b-9, TIMP-3, amyloid P, and lipids. It was not specified whether MPGN was of type I or type II, but material within the drusen was electron-dense and electron-lucent [22]. The lesions observed in our patient were completely transluscent on OCT, representing serous PEDs. In the literature, various lesions such as drusen, PEDs, drusenoid PEDs were reported in patients with C3GN [21, 22]. These lesions may represent a continuum of the same phatophysiologic process involving the accumulation of material in the subretinal space. This may result in a decrease of retinal function, as revealed by abnormally lower elecroretinography responses and reduced sensitivity in areas of high density.

MPGN II can be associated with choroidal neovascularization and central serous chorioretinopathy (CSCR)-like findings [9, 23-27]. As MPGN I and II are part of a spectrum of the same C3 glomerulopathies, patients with 

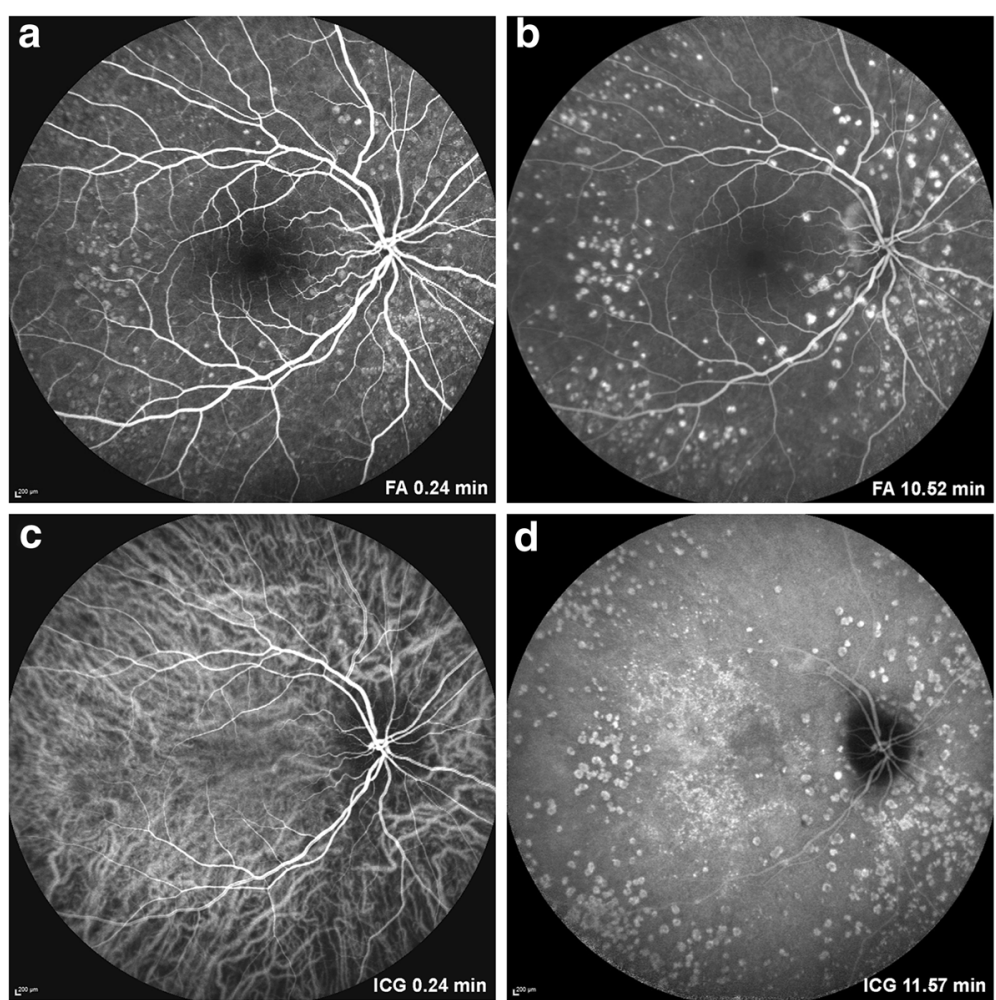

Fig. 4 a and b: RE fluorescein angiography shows hyperfluorescent well circumscribed lesions on early and late time frames. $\mathbf{c}$ and $\mathbf{d}$ : RE indocyanine angiography at early and late phase: late hypercyanescence of the retinal lesions in both eyes

either type of disease should be regularly checked in order to identify and prevent ophthalmologic complications.

Various retinal imaging studies have been described in patients affected by C3 glomerulopathy. First of all, SD OCT is useful on a routine basis for all patients with retinal disease. It helps to define exactly which layers of the retina are affected by the disease, and allows the diagnosis of any secondary complication (choroidal neovascularization, $\mathrm{CNV}$ or atrophy). In the literature, many structural alterations in outer retinal layers and RPE were reported in patients with C3 glomerulopathy: irregularities in RPE surface, lucent or tent-shaped RPE detachments or elevations, subRPE drusenoid deposits, areas of compression of the photoreceptor layer, missing inner segments/outer segments IS/OS and external limiting membrane ELM back-reflection $[1,2,11,26,28]$. A prototype highspeed ultrahigh optic coherence tomography (UHROCT) with an axial resolution of approximately $3 \mu \mathrm{m}$ in tissue was realized in the left eye of a 29-year-old man, affected by drusen-like deposits in the context of C3 glomerulopathy. The UHR-OCT showed not
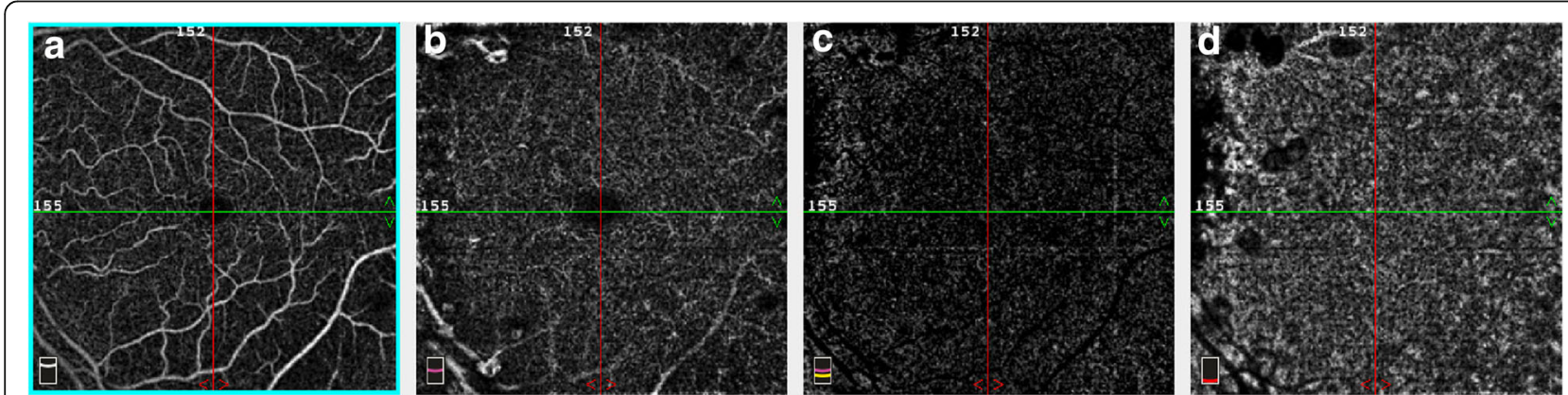

Fig. 5 LE OCT angiography (OCTA). a and (b): In the superficial and deep capillary plexus: no abnormalities. c and (d): In the outer retina and choriocapillaris layers: no vascular membranes associated with PEDs, but rarefaction of vascular network, with a decrease of blood vessels in the choriocapillaris layer 


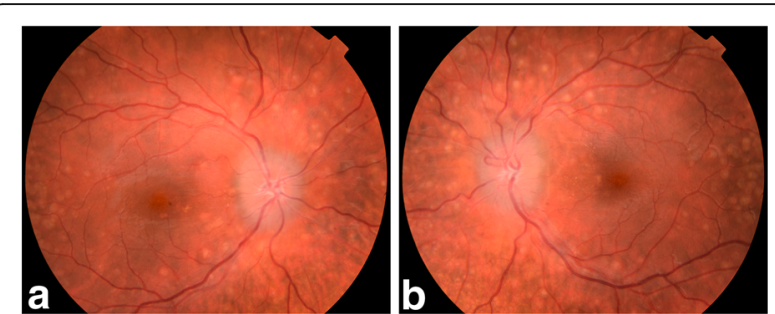

Fig. 6 a. RE fundus. b. LE fundus. Bilateral papillary edema and bilateral multiple PEDs

only RPE detachment, but also an irregular and prominent Bruch's membrane measuring between 9 and $13 \mu \mathrm{m}$ at 3 locations, compared to that of healthy patients being between 2 and $4.7 \mu \mathrm{m}$. It seems to be an interesting tool, because it permits the delineation of Bruch's membrane from RPE, which is not possible with the commercially available SDOCT that has an axial resolution in tissue of 5 to $7 \mu \mathrm{m}[9]$.

Another useful exam is fluorescein and indocyanine green angiography. Drusen without any complications have been described as having a starry sky appearance on fluorescein angiography [2]. Early phase typically shows window defects due to basal lamina drusen, and late phases typically show staining of hyperfluorescence with no evidence of fluid leakage $[1,7,13$, $21,29,30]$. Indocyanine green angiography helps in excluding or identifying choroidal neovascular membranes or CSCR-like lesions as possible complications $[9,21]$. Fluorescein angiograms may show normal results, while penetrating ratios detected by vitreous fluorophotometry readings can be abnormally high, as demonstrated by Raines et al. in 1989. This indicates a breakdown of the blood retinal barrier as a consequence of retinal pigment epithelium dysfunction due to Bruch's membrane deposits [17]. This imaging technique is not, however, used on a routine basis.

Other authors reported microperimetry results, and showed that eyes of patients with C3 glomerulopathy may have reduced sensitivity in areas of high drusen density, probably indicating areas of reduced retinal function $[13,28]$.

Electophysiologic tests can also provide information about retinal function. Leys et al. reported electrooculogram (EOG) results to be normal in patients without choroidal neovascularization and abnormal in patients with choroidal neovascularization (reduced light peak/dark peak) on EOG [20]. Contrary to this, C O'Brien et al. reported 3 asymptomatic patients with typical drusen-like lesions seen in the posterior pole, who had abnormally low Arden ratios on EOG but normal elecro-retinography responses (PERG, Flash-ERG, Flicker ERG). This was the first report of choriocapillaris and Bruch's membrane disease causing electroculographic abnormality without any visual deficit [31]. Lahbil et al. also reported a case of bilateral retinal drusen in a context of C3 glomerulopathy where the ERG was normal [30]. In the presence of retinal complications such as widespread chorioretinal atrophy, EOG, ERG, multifocal ERG and dark adaptation can all show abnormalities [2, 32].

Fluorescein angiography is a useful diagnostic test, but requires injection of fluorescein dye that can be contraindicated in patients with advanced kidney disease. Table 1 resumes the exams used by previous authors to describe drusen. We highlight in this paper the possibility of using OCT angiography in these patients. This is a new retinal imaging technique that allows analysis of the retinal plexuses and choroidal vessels without injecting any dye, and can also identify neovascular membranes. To our knowledge this is the first report of OCTA of multifocal PEDs associated with C3 glomerulopathy.

PEDs in MPGN have been shown to spontaneously resolve [29], but generally the longer the renal disease is present, the greater their evolution, becoming more numerous with later atrophic changes $[12,15,16]$. Subretinal membranes, macular detachment and central serous retinopathy may occur. Some treatments, such as corticosteroids, immunosuppressants and plasmapheresis have been used in these patients to treat the renal disease, but they did not improve the retinal condition. Recently, a newer drug was used in C3 glomerulopathy [intravenous eculizumab (monoclonal antibody that inhibits C5 and prevents formation of the C5b-9 membrane attack complex)] and resulted in substantial improvement of proteinuria, but it had no effect on retinal accumulation of cascade degradation products.

In patients with C3 glomerulopathy, regular ophthalmologic examination should be carried out in order to identify retinal complications early in their development. For patients having undergone a renal graft, ophthalmologic follow-up should be continued as the disease has been reported to recur in these cases [33].

Multimodal imaging of retina with OCT and OCT angiography could be useful in patients with C3 glomerulopathy, to help to identify early retinal manifestations of the disease and enable diagnosis of possible complications at an earlier stage. These patients may develop neovascular membranes, so OCTA appears to be a useful exam to identify this complication without the need to use contrast products that could affect renal function. Considering the progression of retinopathy and potential retinal complications in C3 glomerulopathies, close ophthalmologic follow-up is recommended, even after a renal graft. 
Table 1 This table resumes the exams used by previous authors to describe retinal drusen

\begin{tabular}{|c|c|c|c|c|c|}
\hline $\begin{array}{l}\text { Authors, } \\
\text { Journal (Year of publication) }\end{array}$ & $\begin{array}{l}\text { Number } \\
\text { of cases }\end{array}$ & Symptoms & Clinical findings & Imaging Findings & Lesions \\
\hline $\begin{array}{l}\text { Savige J et al., Ophthalmic } \\
\text { Genet (2016) }\end{array}$ & 6 & $\begin{array}{l}\text { visual acuity normal or } \\
\text { near normal initially. First } \\
\text { symptom: impaired night } \\
\text { vision, progression to loss } \\
\text { of peripheral vision }\end{array}$ & $\begin{array}{l}\text { bilateral symmetrical drusen. } 2 \\
\text { types: } 1 \text {. basal laminar drusen = } \\
\text { small, numerous, yellow. } 2 \text {. large } \\
\text { soft whitish-yellow. Retinal } \\
\text { atrophy after } 15 \text { years and } \\
\text { choroidal neovascularization }\end{array}$ & $\begin{array}{l}\text { OCT: irregularities in RPE surface, } \\
\text { RPE detachments, neovascular } \\
\text { membranes. Fluorescein angiography: } \\
\text { starry sky appearance of druse, multiple } \\
\text { small hyperfluorescent spots throughout } \\
\text { retina and complications. Amsler } \\
\text { grid:distorsion with late complications } \\
\text { multifocal ERG: lower amplitudes and } \\
\text { lower peak amplitude with retinal atrophy }\end{array}$ & $\begin{array}{l}\text { typical drusen, } \\
\text { PED, CNV and } \\
\text { atrophy }\end{array}$ \\
\hline
\end{tabular}

Dalvin LA et al., Retin Cases 2 Brief Rep (2016)

Adhi M et al., Ophthalmic Surg Lasers Imaging Retina (2014)

Empeslidis T et al., Case Rep Ophthalmol Med (2012)

1. VA $20 / 300$ in both eyes with eccentric fixation2. VA 20/20 in both eyes

progressive loss of vision hemorrhage and subretinal secondary to CNV in RE and new distorsion of vision in the LE

problems with near vision signs consistent with RPE tasks

etachments and small drusen-like lesions $\begin{aligned} & \text { Ritter } \mathrm{M} \text { et al., } \mathrm{Br} \mathrm{J} \\ & \text { Ophthalmol (2010) }\end{aligned}$
$\begin{aligned} & \text { VA normal or slightly } \\ & \text { reduced }\end{aligned}$

Han et al., Arch Ophthalmol (2009)

Amer Awan $\mathrm{M}$ et al, Clin Exp Optom (2008)

Shenoy R et al., Eur

Ophthalmol (2006)

VA normal in LE, and 20/

30 in RE

blurring vision, micropsia metamorphopsia

poor night vision

Kidnille D et al., Am

Kidney Dis (2003)

occasional drusen, widespread chorioretinal atrophy, macular pigmentation

$\begin{array}{lll}\begin{array}{l}\text { Lahbil D et al., J Fr } \\ \text { Ophtalmol (2002) }\end{array} & 1 & \begin{array}{l}\text { important decrease of } \\ \text { visual acuity in both eyes }\end{array} \\ \text { Mullins RF et al., Eye (2001) } & 2 & \\ & 1 & \begin{array}{l}\text { blurred vision in right } \\ \text { eye, with visual acuity } \\ 20 / 20 \text { in RE, and 20/200 } \\ \text { in LE }\end{array}\end{array}$

Lahbil D et al., J Fr

in LE drusen: temporal in early cases, and throughout the retina in advanced cases

bilateral multifocal, 200-300um yellowish lesions at choroid and subretinal pigment epithelial level

elevated area overlying the macula in both eyes. Multiple pale areas without any drusen. Peripheral retina normal in both eyes.

multiple drusen-like lesions us subretinal deposits similar to drusen seen in AMD

fine drusen in both eyes Neurosensory detachment in the nasal macula of $R E$, and disciform scar in LE
$\mathrm{OCT}$ : drusen Fluorescein angiography: areas of hypofluorescence corresponding to subretinal fibrosis surrounded by leakage, window defects, andmultiple drusen

OCT: RPE detachment, irregular and prominent Bruch's membrane ICG angiography: no definitive signs of CNV

OCT: PEDs, intraretinal fluid in a cystoid form of less than 50um in the inner retinal layers. No subretinal fluidFluorescein angiography: early phase: window defect due to basal lamina drusen; late phase: staining of hyperfluorescence. No leakage. RPE layer intact.

OCT: RPE elevations, areas of compression of the photoreceptor layer missing of IS/OS and ELM backreflection Microperimetry: reduced sensitivity in areas of high drusen density

OCT: lucent focal elevations of RPE Fluorescein and indocyanine Angiography: staining of lesions throughout the fundi, more numerous than those observed by ophthalmoscopy

OCT: tent-shaped RPE detachment with overlying detachment of neurosensory retina and loss of foveolar contour Fluorescein Angiography: early multiple hyperfluorescence areas corresponding to these pale areas. Mid-phase leakage of dye in subretinal space

Microperimetry: areas of reduced retinal sensitivity in areas which were laden with drusen-like deposits, probably indicating areas of reduced retinal function OCT: drusen Fluorescein Angiography: multiple window defects in the posterior pole of both eyes corresponding to the drusen-like lesions

dark adaption test: uniphasic- > consistent with severe rod dysfunction ERG: delayed rod and delayed combined rod and cone responses EOG: reduced light peak/dark through (or Arden ratio) possibly reflecting an ocbstruction to the passage of metabolites from the choriocapillaris Fluorescein angiography: subfoveal choroidal neovascularization

Fluorescein Angiography: after resorbtion of serous fluid, punctiform hyperfluorescent lesions still staining at late phase. ERG:normal

histochemistry/ immunohistochemistry: same composition of drusen in AMD

typical drusen, subretinal fibrosis

PED, suspicion of CNV

typical drusen. PED, intraretinal fluid with no subretinal fluid. No CNV

typical drusen

typical drusen

atypical idiopathic serous central chorioretinopathy with spontaneous resolution at 6 weeks

typical drusen

drusen, CNV and atrophy

Fluorescein agiography: multiple discrete hyperfluorescent spots corresponding to drusen, and early and late staining at RPE level in the area of the detachment, with 4
CRSC- like lesion

typical drusen

neurosensory detachment with spontaneous resolution at 2 weeks 
Table 1 This table resumes the exams used by previous authors to describe retinal drusen (Continued)

\begin{tabular}{|c|c|c|c|c|c|}
\hline $\begin{array}{l}\text { Authors, } \\
\text { Journal (Year of publication) }\end{array}$ & $\begin{array}{l}\text { Number } \\
\text { of cases }\end{array}$ & Symptoms & Clinical findings & Imaging Findings & Lesions \\
\hline & & & & $\begin{array}{l}\text { pinpoints sites of late leakage. } \\
\text { Minimal pooling of dye in the subretinal space. }\end{array}$ & \\
\hline $\begin{array}{l}\text { C O'Brien et al., Br J } \\
\text { Ophthalmol (1993) }\end{array}$ & 4 & asymptomatic & $\begin{array}{l}\text { multiple, yellow, drusen-like } \\
\text { lesions }\end{array}$ & $\begin{array}{l}\text { EOG: abnormal low Arden ratios } \\
\text { PERG, flash ERG, and flicker ERG: } \\
\text { waveform amplitudes essentially } \\
\text { normal for all } 4 \text { subjects }\end{array}$ & typical drusen \\
\hline $\begin{array}{l}\text { Leys A et al., Graefes Arch } \\
\text { Clin Exp Ophthalmol (1991) }\end{array}$ & 23 & - & $\begin{array}{l}\text { small-sized subretinal nodules } \\
\text { simulating basal laminar drusen. } \\
4 \text { patients displayed marked } \\
\text { retinopathy and3 of them } \\
\text { exhibited subretinal } \\
\text { neovascularization }\end{array}$ & $\begin{array}{l}\text { EOG: Light Peak/Dark peak ratio } \\
\text { reduced in } 4(36 \%) \text { of the } 11 \\
\text { patients with EOG recordings. } \\
\text { EOG and visual field: grossly } \\
\text { normal in patients who did } \\
\text { not exhibit choroidal neovascularization. }\end{array}$ & $\begin{array}{l}\text { Typical drusen, } \\
\text { CNV }\end{array}$ \\
\hline $\begin{array}{l}\text { Leys A et al., Pediatr } \\
\text { Nephrol (1991) }\end{array}$ & 3 & - & granular retinal changes & $\begin{array}{l}\text { Fluorescein angiography: } \\
\text { numerous basal laminar drusen }\end{array}$ & drusen \\
\hline $\begin{array}{l}\text { Leys A et al., Eur J } \\
\text { Ophthalmol (1991) }\end{array}$ & 4 & decrease of vision & drusenoid lesions & $\begin{array}{l}\text { Fluorescein angiography: } \\
\text { neovascular membranes }\end{array}$ & CNV \\
\hline $\begin{array}{l}\text { Duvall-Young J et al., Br J } \\
\text { ophthalmol (1989) }\end{array}$ & 1 & VA $6 / 24$ in both eyes & normal fundus & $\begin{array}{l}\text { Fluorescein angiography: } \\
\text { numerous hyperfluorescent } \\
\text { discrete foci at posterior pole, } \\
\text { becoming more intensely } \\
\text { fluorescent with time }\end{array}$ & typical drusen \\
\hline $\begin{array}{l}\text { Duvall-Young J et al., Br J } \\
\text { ophthalmol (1989) }\end{array}$ & 11 & asymptomatic & few drusen & $\begin{array}{l}\text { Fluorescein angiography: few } \\
\text { hyperfluoresent spots corresponding } \\
\text { to scattered drusen }\end{array}$ & typical drusen \\
\hline $\begin{array}{l}\text { Raines MF et al., Br J } \\
\text { Ophthalmol (1989) }\end{array}$ & 5 & asymptomatic & drusen & $\begin{array}{l}\text { Vitreous Fluorophotometry: Breakdown } \\
\text { of the blood retinal barrier: vitreous } \\
\text { fluorophotometry readings and } \\
\text { penetration ratios abnormally } \\
\text { high, indicating that the deposits } \\
\text { in Bruch's membrane cause retinal } \\
\text { pigment epithelial dysfunction. } \\
\text { Fluorescein angiography: normal. }\end{array}$ & typical drusen \\
\hline
\end{tabular}

\section{Abbreviations}

AMD: Age-related macular degeneration; C3: Complement 3;

C3GN: Complement 3 glomerulonephropathy; CSCR: Central serous chorioretinopathy; ELM: External limiting membrane; EOG: Electrooculogram; ERG: Electroretinogram; IS/OS: Inner segment /outer segment; MPGN: Membranoproliferative glomerulonephritis; OCTA: Optic coherence angiography; PEDs: Pigment epithelial detachments; PERG: PatternElectroretinogram; RPE: Retinal pigment epithelium; UHR-OCT: Ultrahighresolution optical coherence tomography

\section{Acknowledgements}

Dr. Samuel Rotman for providing electron microscopy images of the kidney.

\section{Authors'contributions}

-VK. wrote the greater part of the article, and reviewed the literature. -AD. participated in the writing of the article and realized the OCTA images.. $-\mathrm{MH}$. is the nephrologist in charge of the patient and participated in the description of the kidney disease. -JPV. and GH. revised the section dedicated to renal disease. -YGC. followed the patient in his department, provided the clinical files about the retinal disease, and supervised the final article. All authors have read and approved the final version of this manuscript.

\section{Funding}

No specific funding was received for this study.

\section{Availability of data and materials}

No datasets were generated during the current study, but further patient information is available from the corresponding author on reasonable request.

Ethics approval and consent to participate Not applicable

\section{Consent for publication}

Written informed consent was obtained from the patient for publication of this case report and any accompanying images (no identifying patient data). A copy of the written consent is available for review by the Editor of this journal.

Competing interests

The authors declare that they have no competing interests.

\section{Publisher's Note}

Springer Nature remains neutral with regard to jurisdictional claims in published maps and institutional affiliations.

\section{Author details}

1Jules Gonin Eye Hospital, Department of Ophthalmology, University of Lausanne, Ave de France 15, 1000 Lausanne 2, Switzerland. ${ }^{2}$ Service de Néphrologie du CHUV, Université de Lausanne, Lausanne, Switzerland. ${ }^{3}$ Centre hospitalier universitaire vaudois (CHUV), Centre de transplantation d'organes, Université de Lausanne, Lausanne, Switzerland.

Received: 18 October 2016 Accepted: 14 November 2017

Published online: 22 November 2017

\section{References}

1. Dalvin LA, et al. Shedding light on Fundus Drusen associated with Membranoproliferative Glomerulonephritis: breaking stereotypes of types I, ii, and iii. Retin Cases Brief Rep. 2016;10(1):72-8.

2. Savige J, et al. Retinal disease in the $\mathrm{C} 3$ glomerulopathies and the risk of impaired vision. Ophthalmic Genet. 2016;37(4):369-76.

3. Brenner, Pathogenesis of renal disease. The Kidney, 2004. 1: p. 1322-1327.

4. Sethi S, Fervenza FC. Membranoproliferative glomerulonephritis: pathogenetic heterogeneity and proposal for a new classification. Semin Nephrol. 2011;31:341-8. 
5. Appel GB, et al. Membranoproliferative glomerulonephritis type II (dense deposit disease): an update. J Am Soc Nephrol. 2005;16(5):1392-403.

6. YB D'S, et al. Oligosaccharide composition is similar in drusen and dense deposits in membranoproliferative glomerulonephritis type II. Kidney Int. 2009;75(8):824-7.

7. Duvall-Young J. Fundus changes in mesangiocapillary glomerulonephritis type II: clinical and fluorescein angiographic findings. Br J Ophthalmol. 1989; 73(11):900-6.

8. Awan B. Macular sub-retinal fluid and retinal pigment epithelial detachment associated with type 2 membrano-proliferative glomerulonephritis. Clin Exp Optom. 2007;91(5):476-9.

9. Adhi $\mathrm{M}$, et al. High-speed ultrahigh-resolution OCT of Bruch's membrane in membranoproliferative glomerulonephritis type 2. Ophthalmic Surg Lasers Imaging Retina. 2014;45(6):614-7.

10. O'Brien C, et al. Electrophysiology of type II mesangiocapillary glomerulonephritis with associated fundus abnormalities. Br J Ophthalmol. 1993:77(12):778-80.

11. Empeslidis T, et al. Spontaneous resolution of retinal pigment epithelial detachments and visual improvement in patient with MPGN II: a case report. Case Rep Ophthalmol Med. 2012;2012:864198.

12. Leys $A$, et al. Sequential observation of fundus changes in patients with long standing membranoproliferative glomerulonephritis type II (MPGN type II). Eur J Ophthalmol. 1991;1(1):17-22.

13. Shenoy R, McCilvenny S. Microperimetric evaluation of macula in retinopathy of membranoproliferative glomerulonephritis type II: a case report. Eur J Ophthalmol. 2006;16(4):634-6.

14. Polk TD, et al. Subretinal fluid associated with membranoproliferative glomerulonephritis type 2. Arch Ophthalmol. 1997;115(7):927-8.

15. McAvoy CE, Silvestri G. Retinal changes associated with type 2 glomerulonephritis. Eye (Lond). 2005;19(9):985-9.

16. Leys $A$, et al. Specific eye fundus lesions in type II membranoproliferative glomerulonephritis. Pediatr Nephrol. 1991;5(2):189-92.

17. Raines MF, Duvall-Young J, Short CD. Fundus changes in mesangiocapillary glomerulonephritis type II: vitreous fluorophotometry. Br J Ophthalmol. 1989;73(11):907-10.

18. Colville $\mathrm{D}$, et al. Visual impairment caused by retinal abnormalities in mesangiocapillary (membranoproliferative) glomerulonephritis type II ("dense deposit disease"). Am J Kidney Dis. 2003:42(2):E2-5.

19. Huang SJ, et al. Peripheral drusen in membranoproliferative glomerulonephritis type II. Retina. 2003;23(3):429-31.

20. Leys $A$, et al. Fundus changes in membranoproliferative glomerulonephritis type II. A fluorescein angiographic study of 23 patients. Graefes Arch Clin Exp Ophthalmol. 1991;229(5):406-10.

21. Han DP, Sievers S. Extensive drusen in type I membranoproliferative glomerulonephritis. Arch Ophthalmol. 2009;127(4):577-9.

22. Mullins RF, Aptsiauri N, Hageman GS. Structure and composition of drusen associated with glomerulonephritis: implications for the role of complement activation in drusen biogenesis. Eye (Lond). 2001;15(Pt 3):390-5.

23. Michielsen $B$, et al. Fundus changes in chronic membranoproliferative glomerulonephritis type II. Doc Ophthalmol. 1990;76(3):219-29.

24. Hassenstein A, Richard G. Choroidal neovascularisation in type /I membranoproliferative glomerulonephritis, photodynamic therapy as a treatment option-a case report. Klin Monatsbl Augenheilkd. 2003: 220(7):492-5

25. Ulbig MR, et al. Membranoproliferative glomerulonephritis type II associated with central serous retinopathy. Am J Ophthalmol. 1993;1 16(4):410-3.

26. Awan MA, Grierson DJ, Walker S. Bilateral macular sub-retinal fluid and retinal pigment epithelial detachment associated with type 2 membrano-proliferative glomerulonephritis. Clin Exp Optom. 2008;91(5): $476-9$

27. Framme C, et al. Subretinal neovascular membranes in membranoproliferative glomerulonephritis type II. Klin Monatsbl Augenheilkd. 1998;213(4):252-3.

28. Ritter $\mathrm{M}$, et al. Functional and morphological macular abnormalities in membranoproliferative glomerulonephritis type II. Br J Ophthalmol. 2010; 94(8):1112-4.

29. Empeslidis T. Spontaneous resolution of retinal pigment epithelial detachment and visual Improvment in patient with MPGN II: a case report. Case Rep Ophthalmol Med. 2012:864198. doi:10.1155/2012/864198. Epub 2012 Dec 5.

30. Lahbil D. Atteinte oculaire au cours de la glomerulonéphrite membranoproliférative type II. J Fr Ophthalmol. 2002;25(9):949-54
31. O'Brien C. Electrophysiology of type II mesangiocapillary glomerulonephritis with associated fundus abnormalies. Br J Ophthalmol. 1993;77:778-80.

32. Colville D. Visual impairement caused by retinal abnormalities in mesangiocapillary (membranoproliferative) glomerulonephritis type II ("dense deposit disease"). Am J Kidney Dis. 2003;42(2):E2-5.

33. Gass JD. Posterior chorioretinopathy and retinal detachment after organ transplantation. Arch Ophthalmol. 1992;110(12):1717-22.

\section{Submit your next manuscript to BioMed Central and we will help you at every step:}

- We accept pre-submission inquiries

- Our selector tool helps you to find the most relevant journal

- We provide round the clock customer support

- Convenient online submission

- Thorough peer review

- Inclusion in PubMed and all major indexing services

- Maximum visibility for your research

Submit your manuscript at www.biomedcentral.com/submit
C) BioMed Central 